Info Artikel Diterima Maret 2019

Disetujui Juni 2019

Dipublikasikan Oktober 2019

\title{
ANALISIS USAHA PENGOLAHAN ABON LELE DI DESA TEGALREJO KECAMATAN SAWIT KABUPATEN BOYOLALI
}

\section{ANALYSIS OF SHREDDED-CATHFISH PROCESSING BUSINESS IN TEGALREJO VILLAGE SAWIT DISTRICT BOYOLALI REGENCY}

\author{
Fuad Hanif Nur Kholis*, Lutfi Aris Sasongko, Aniya Widiyani \\ Program Studi Agribisnis Fakultas Pertanian \\ Universitas Wahid Hayim Semarang \\ *Email: fuadkholis43@gmail.com
}

\begin{abstract}
Shredded-catfish processing business is a business that produces floss with raw catfish as the main ingredient. The business of shredded-catfish in Boyolali Regency located in Kampung Lele, Tegalrejo Village, Sawit District. Shreddedcatfish become the superior product in Boyolali and the surrounding areas. The purpose of this research are to determine the total production costs, the level of revenue, income, and feasibility of the shredded-catfish processing business in Tegalrejo Village, Sawit District, Boyolali Regency. The basic method that used in research was using descriptive analitycal method. Determination of the sample location was carried out purposely in Tegalrejo Village, Sawit District, Boyolali Regency. The data used are primary and secondary data. Data retrieval method used are interview, observation and recording. There are 23 respondents in this study from some business groups i.e Karmina, Pamuji and Alang-Alang. Data analysis method used are cost, revenue, income, R/C and BEP analysis. Research result from the study of shredded-catfish processing business in Karmina, Pamuji and Alang-Alang business group for one month respectively cost as much as Rp 24.043.591; Rp 26.055.548; and Rp 8.397.784. Those total cost consist of the cost of raw materials, fuel, packaging, depreciation of equipment, employee wages and electricity. Karmina group produces $276 \mathrm{~kg}$ of shredded catfish at a price of $\mathrm{Rp}$ $120.000 / \mathrm{kg}$. Pamuji Group produces $336 \mathrm{~kg}$ of shredded catfish at a price of $\mathrm{Rp}$ $110.000 / \mathrm{kg}$. Alang-Alang group produces $120 \mathrm{~kg}$ at a price of $\mathrm{Rp} 110.000 / \mathrm{kg}$, so the total revenue of the Karmina group is Rp 33.120.000; Pamuji group's total

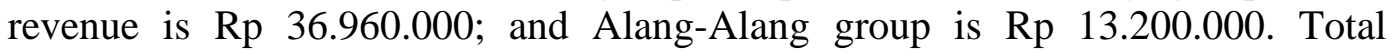

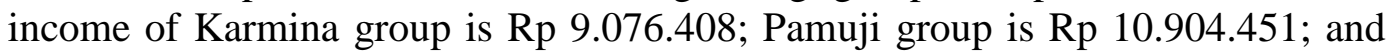
Alang-Alang group is $\mathrm{Rp}$ 4.802.215. The $\mathrm{R} / \mathrm{C}$ values of the Karmina, Pamuji and Alang-Alang business group are respectively 1,$37 ; 1.41 ; 1.57$, so the business is feasible to do. The BEP unit value in the Karmina group is $100,36 \mathrm{~kg}$, Pamuji group is $236,86 \mathrm{~kg}$ and Alang-Alang group is $76,34 \mathrm{~kg}$, while the BEP price value in the Karmina group is Rp. 87,114.44; Pamuji group is Rp 77,546.27; and AlangAlang group is Rp 69,981,53.
\end{abstract}

Keywords: business analysis, shredded-catfish, $R / C, B E P$ 


\begin{abstract}
ABSTRAK
Usaha pengolahan abon lele merupakan usaha yang memproduksi abon dengan bahan baku utama ikan lele. Produksi abon lele di Kabupaten Boyolali berada di Kampung Lele Desa Tegalrejo Kecamatan Sawit Abon lele menjadi produk andalan hasil olahan ikan lele di wilayah Boyolali dan sekitarnya. Tujuan penelitian ini untuk mengetahui total biaya produksi, tingkat penerimaan, pendapatan, dan kelayakan dari usaha pengolahan abon lele di Desa Tegalrejo Kecamatan Sawit Kabupaten Boyolali. Metode dasar penelitian yang digunakan adalah deskriptif analitis. Penentuan sampel lokasi dilakukan secara sengaja yaitu di Desa Tegalrejo Kecamatan Sawit Kabupaten Boyolali. Data yang digunakan adalah data primer dan sekunder. Metode pengambilan data dengan wawancara, observasi, dan pencatatan. Responden dalam penelitian ini sebanyak 23 responden yang berasal dari Kelompok Usaha Karmina, Pamuji, dan Alang-alang. Analisis data yang digunakan yaitu dengan analisis biaya, penerimaan, pendapatan, R/C dan BEP. Dari analisis usaha pengolahan abon lele di Kelompok Karmina, Pamuji, dan Alang-alang selama 1 bulan berturut-turut menghasilkan biaya total sebesar Rp 24.043.591; Rp 26.055.548; dan Rp 8.397.784. Biaya terdiri dari biaya bahan baku, bahan bakar, pengemasan, penyusutan alat, gaji karyawan, dan listrik. Satu bulan produksi, Kelompok Karmina memproduksi $276 \mathrm{~kg}$ abon dengan harga Rp 120.000/kg; Kelompok Pamuji memproduksi $336 \mathrm{~kg}$ abon dengan harga Rp 110.000/kg; Kelompok Alang-alang memproduksi $120 \mathrm{~kg}$ dengan harga $\mathrm{Rp}$ $110.000 / \mathrm{kg}$, sehingga total penerimaan Kelompok Karmina sebesar Rp Rp 33.120.000; Kelompok Pamuji sebesar Rp 36.960.000; Kelompok Alang-alang sebesar Rp 13.200.000. Total pendapatan Kelompok Karmina sebesar Rp 9.076.408; Kelompok Pamuji sebesar Rp 10.904.451; Kelompok Alang-alang sebesar Rp 4.802.215. Nilai R/C Kelompok Karmina, Pamuji, dan Alang-alang berturut-turut adalah 1,$37 ; 1,41 ; 1,57$, sehingga usaha tersebut layak diusahakan. Nilai BEP unit di Kelompok Karmina sebesar 200,36 kg, Kelompok Pamuji sebesar 236,86 kg, Kelompok Alang-alang sebesar 76,34 kg, sedangkan BEP rupiah di Kelompok Karmina sebesar Rp 87.114,44; Kelompok Pamuji sebesar Rp 77.546,27; Kelompok alang-alang sebesar Rp 69.981,53.
\end{abstract}

\title{
Kata Kunci : Analisis Usaha, Abon Lele, R/C, BEP
}

\section{PENDAHULUAN}

Negara Indonesia adalah negara agraris yang memiliki potensi alam yang sangat luas. Salah satu potensi alam yang prospektif adalah potensi perikanan. Indonesia memiliki perairan tawar yang sangat luas dan berpotensi besar untuk usaha budidaya perikanan. Menurut Statistik DJPB (2011), Sumberdaya perairan Indonesia meliputi perairan umum (sungai, waduk dan rawa), sawah (mina padi), dan kolam dengan total luas lahan 605.990 hektar. Perairan umum seluas 141.690 hektar, sawah (mina padi) seluas 88.500 hektar, dan perairan kolam seluas 375.800 hektar.

Ikan Lele dapat dibudidayakan di kolam air tawar yang merupakan perikanan tangkap. Menurut data BPS Kabupaten Boyolali tahun 2016, produksi 
perikanan kolam tertinggi terdapat di Kecamatan Sawit dengan jumlah produksi sebesar 10.511,3 ton.

Tabel 1. Produksi Perikanan Tangkap Menurut Kecamatan dan Subsektor di Kabupaten Boyolali (Ton) Tahun 2016

\begin{tabular}{lllllll}
\hline Kecamatan & Tambak Kolam Keramba & $\begin{array}{l}\text { Jaring } \\
\text { Apung }\end{array}$ & Sawah & Total
\end{tabular}

\begin{tabular}{lcccccc}
\hline Selo & - & 6,1 & - & - & - & - \\
Ampel & - & 344,9 & - & - & - & - \\
Cepogo & - & 112,6 & - & - & - & - \\
Musuk & - & 321,7 & - & - & - & - \\
Boyolali & - & 706,0 & - & - & - & - \\
Mojosongo & - & 598,4 & - & - & - & - \\
Teras & - & 8541,6 & - & - & - & - \\
Sawit & - & $\mathbf{1 0 5 1 1 , 3}$ & - & - & - & - \\
Banyudono & - & 785,3 & - & - & - & - \\
Sambi & - & 516,4 & 125,2 & - & - & - \\
Ngemplak & - & 747,0 & 2488,7 & - & - & - \\
Nogosari & - & 189,9 & - & - & - & - \\
Simo & - & 962,2 & - & - & - & - \\
Karanggede & - & 582,9 & - & - & - & - \\
Klego & - & 91,7 & - & - & - & - \\
Andong & - & 70,8 & - & - & - & - \\
Kemusu & - & 99,5 & 5131,8 & - & - & - \\
Wonosegoro & - & 13,3 & - & - & - & - \\
Juwangi & - & 78,9 & - & - & - & - \\
\hline Jumlah & - & $\mathbf{2 5 2 8 0 , 5}$ & $\mathbf{7 7 4 5 , 7}$ & - & - & - \\
\hline
\end{tabular}

Sumber : Badan Pusat Statistik Kabupaten Boyolali Tahun 2016

Tingkat konsumsi ikan yang semakin meningkat merupakan suatu peluang bagus untuk mengembangkan sektor perikanan. Sektor perikanan terbagi menjadi tiga sub sektor yaitu perikanan laut, perikanan budidaya dan perikanan perairan umum. Salah satu sub sektor perikanan yang memiliki peluang untuk dikembangkan adalah perikanan budidaya, dan salah satu komoditas perikanan budidaya yang memiliki peluang besar dikembangkan untuk pemenuhan gizi masyarakat adalah ikan lele.

Ikan lele merupakan salah satu jenis ikan air tawar yang berasal dari Filipina yaitu lele dumbo (Clarias gariepinus) dan lele lokal (Clarias batrachus) dan sudah dibudidayakan secara komersial oleh masyarakat Indonesia terutama di Pulau Jawa. Budidaya lele berkembang pesat dikarenakan 1) dapat dibudidayakan di lahan dan sumber air yang terbatas dengan padat tebar tinggi, 2) teknologi budidaya relatif mudah dikuasai oleh masyarakat, 3) pemasarannya relatif mudah dan 4) modal usaha yang dibutuhkan relatif rendah. 
Kabupaten Boyolali merupakan salah satu wilayah yang menjadi pusat budidaya ikan lele di Jawa Tengah. Pusat budidaya ikan lele tersebut berada di Dusun Mangkubumen, Desa Tegalrejo Kecamatan Sawit. Sebagian besar masyarakat di wilayah tersebut bermata pencaharian sebagai petani lele. Pada tahun 2006, Gubernur Jawa Tengah saat itu Mardiyanto melakukan kunjungan ke wilayah tersebut dan meresmikan wilayah tersebut di beri nama Kampung Lele. Pada tahun 2007, Presiden Susilo Bambang Yudhoyono juga melakukan kunjungan ke kampung lele untuk memberikan bantuan benih lele dan pakan yang digunakan untuk pengembangan sentra produksi lele di wilayah Boyolali. Selain pengembangan budidaya ikan lele, harapan dari Presiden Susilo Bambang Yudhoyono dan Ibu Ani Yudhoyono adalah pengembangan produk ikan lele menjadi makanan olahan khas.

Berdasarkan latar belakang di atas, maka dapat diketahui rumusan masalah sebagai berikut: 1). Berapa total biaya produksi, penerimaan dan pendapatan dari usaha pengolahan abon lele di Desa Tegalrejo Kecamatan Sawit Kabupaten Boyolali?, 2). Berapa tingkat R/C (Revenue Cost Ratio) dan BEP usaha pengolahan abon lele di Desa Tegalrejo Kecamatan Sawit Kabupaten Boyolali?

\section{BAHAN DAN METODE}

Metode yang digunakan dalam penelitian ini adalah metode deskriptif analitis. Menurut Nazir (2005), metode deskriptif analitis merupakan metode penelitian yang menggambarkan fenomena-fenomena yang ada, gambaran secara sistematis, faktual, dan akurat mengenai fakta-fakta, sifat-sifat atau hubungan antar fenomena yang diselidiki.

Penelitian dilaksanakan di Desa Tegalrejo, Kecamatan Sawit, Kabupaten Boyolali. Penentuan lokasi penelitian dilakukan berdasarkan metode purposive sampling. Menurut Supardi (2005), purposive merupakan suatu hal yang harus dibuat kisi-kisi atau batas-batas berdasarkan subjek yang akan dijadikan sampel penelitian, dalam hal ini seseorang harus menetapkan seseorang yang akan dijadikan sampel penelitian. Penentuan lokasi penelitian ini berdasarkan pertimbangan Kecamatan Sawit merupakan sentra budidaya perikanan terbesar di Kabupaten Boyolali. Selain itu sebagian besar warganya menjalankan usaha pengolahan abon lele.

Metode penentuan sampel dalam penelitian ini adalah dengan metode sensus. Menurut Supranto (2000), sensus adalah cara pengumpulan data dimana seluruh elemen populasi diselidiki satu per satu. Sampel yang dipilih merupakan pelaku usaha abon lele di Desa Tegalrejo Kecamatan Sawit Kabupaten Boyolali dengan jumlah populasi sebanyak 23 orang yang berasal dari 3 kelompok usaha pengolahan abon lele, yaitu Kelompok Usaha Karmina, Pamuji, dan Alang-Alang. Analisis data yang digunakan adalah analisis biaya, penerimaan, pendapatan serta $\mathrm{R} / \mathrm{C}$.

\section{a. Biaya}

Menurut Soekartawi (2002) biaya dalam arti luas merupakan pengorbanan sumber ekonomis, yang diukur dalam satuan uang, yang terjadi atau yang kemungkinan akan terjadi untuk mencapai tujuan tertentu. Dalam arti sempit 
diartikan sebagai sumber ekonomi untuk memperoleh aktiva yang disebut dengan istilah harga pokok. Biaya total merupakan keseluruhan jumlah biaya produksi yang dikeluarkan, yaitu merupakan penjumlahan dari biaya tetap dan biaya variabel (Gilarso, 2001) rumus biaya yaitu :

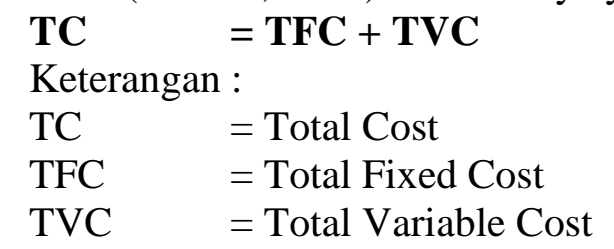

\section{b. Penerimaan}

Menurut Soekartawi (2002), penerimaan dapat diartikan sebagai nilai produk total dalam jangka waktu tertentu baik yang dipasarkan maupun tidak. Penerimaan juga dapat didefinisikan sebagai nilai uang yang diterima dari penjualan. Rumus penerimaan yaitu :

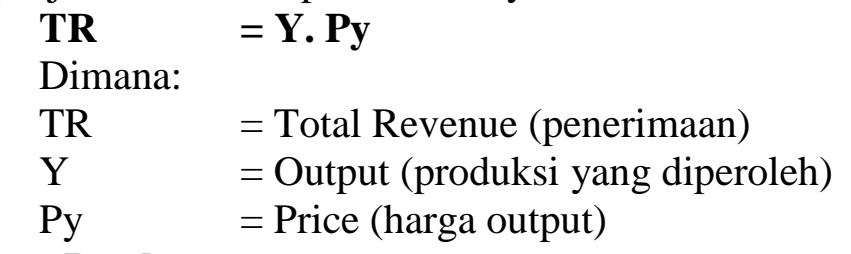

\section{c. Pendapatan}

Menurut Soekartawi (2002), pendapatan merupakan selisih antara penerimaan dan semua biaya dari kegiatan usaha. Pendapatan dapat dirumuskan sebagai berikut :

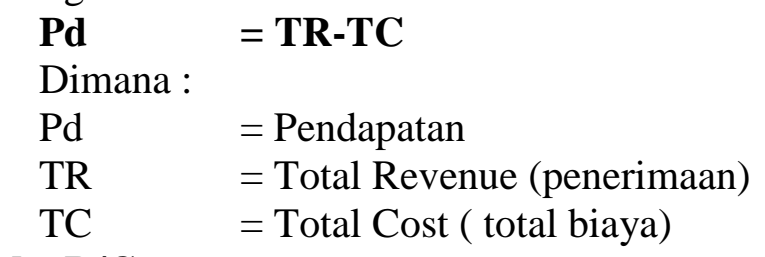

\section{d. $\mathbf{R} / \mathbf{C}$}

Menurut Soekartawi (2002), R/C adalah singkatan dari Revenue Cost Ratio atau dikenal sebagai perbandingan antara penerimaan dan biaya. Secara teoritis dengan rasio $\mathrm{R} / \mathrm{C}=1$ artinya tidak untung dan tidak rugi. Namun, karena adanya biaya usaha yang kadang-kadang tidak dihitung, maka kriterianya dapat diubah menurut keyakinan si peneliti, misalnya R/C lebih dari 1 bila suatu usaha itu dikatakan menguntungkan. Kriteria uji sebagai berikut :

$\mathrm{R} / \mathrm{C}>1$, usaha layak diusahakan

$\mathrm{R} / \mathrm{C}=1$, usaha tidak untung dan tidak rugi (impas)

$\mathrm{R} / \mathrm{C}<1$, usaha tidak layak diusahakan

\section{e. BEP (Break Even Point)}

Menurut Mesra (2012), Break Even Point atau titik impas merupakan konsep yang digunakan untuk menganalisis jumlah minimum produk yang harus dihasilkan atau terjual agar perusahaan tidak mengalami kerugian. Keadaan pulang pokok terjadi apabila TR = TC yang berarti perusahaan tidak mengalami keuntungan atau tidak mengalami kerugian. Analisis BEP digunakan sebagai untuk mencari hubungan antara biaya tetap, biaya variabel, keuntungan, dan volume penjualan. Cara menghitung BEP ada 2 rumus: 
1) BEP atas dasar unit

Perhitungan Break Even Point atas dasar unit menggunakan rumus sebagai berikut:

$\operatorname{BEP}(\mathrm{Q})=\frac{\text { Total biaya }}{\text { Harga }}$

2) BEP atas dasar penjualan dalam rupiah

Perhitungan Break Even Point atas dasar penjualan dalam rupiah menggunakan rumus sebagai berikut:

BEP $($ rupiah $)=\frac{\text { Total biaya }}{\text { Jumlah produksi }}$

\section{HASIL DAN PEMBAHASAN}

a. Analisis Biaya Tetap

Tabel 2. Biaya Tetap Produksi Abon Lele Di Desa Tegalrejo Kecamatan Sawit Kabupaten Boyolali dalam 1 Bulan Produksi

\begin{tabular}{lccc}
\hline \multicolumn{1}{c}{ Keterangan } & \multicolumn{3}{c}{ Biaya Kelompok Usaha (Rp) } \\
& Karmina & Alang-Alang & Pamuji \\
\hline Biaya Penyusutan Alat & 58.964 & 108.532 & 64.684 \\
Gaji Karyawan & 4.320 .000 & 1.200 .000 & 2.880 .000 \\
Biaya Listrik & 54.147 & 119.652 & 56.784 \\
\hline Biaya Tetap (Fixed Cost) & 4.433 .111 & 1.428 .184 & 3.001 .468 \\
\hline
\end{tabular}

Sumber: Analisis Data Primer, 2018.

Tabel 2 diketahui bahwa biaya tetap yang paling besar ada pada kelompok Karmina yaitu sebesar Rp 4.433.111 dan biaya tetap yang paling kecil di Kelompok Alang-Alang yaitu sebesar Rp 1.428.184. Hal ini karena biaya gaji karyawan yang diberikan selama 1 bulan produksi sebesar Rp 4.320.000 untuk 9 orang karyawan dengan intensitas produksi abon lele sebanyak 12 kali, berbeda dengan kelompok Alang-alang walaupun produksi abon kelompok tersebut dikerjakan oleh 10 orang tetapi kelompok Alang-alang intensitas produksi abon lele selama 1 bulan hanya 3 kali sehingga biaya gaji lebih sedikit, demikian juga dengan kelompok Pamuji walaupun intensitas produksi abon lele sebanyak 16 kali dalam 1 bulan tetapi karyawan di kelompok Pamuji hanya 4 orang sehingga biaya gaji karyawan juga lebih sedikit dibandingkan dengan Kelompok Karmina. Dilihat dari biaya penyusutan, dapat diketahui bahwa cost yang tertinggi justru di Kelompok Alang-alang karena harga beli peralatan produksi abon lele yang lebih tinggi dibandingkan dengan harga beli peralatan produksi abon lele di Kelompok Pamuji dan Karmina. Demikian juga dengan biaya listrik tertinggi justru di Kelompok Alang-alang karena daya pakai penggunaan spinner dan sealer di Kelompok Alang-alang lebih tinggi dibandingkan dengan 2 kelompok lainnya. b. Analisis Biaya Variabel

Tabel 3 diketahui bahwa biaya variabel yang dikeluarkan dari proses pembuatan abon lele di ketiga kelompok pengolah abon berbeda. Biaya variabel di Kelompok Usaha Pamuji paling tinggi dibandingkan di Kelompok Karmina dan 
Alang-alang yaitu $\mathrm{Rp}$ 23.054.080. Faktor yang menyebabkan variable cost tinggi salah satunya biaya bahan baku meliputi bahan baku lele segar. Bahan baku lele segar yang dibutuhkan dalam pembuatan abon lele di kelompok Pamuji sebenarnya hanya $70 \mathrm{~kg}$ dibandingkan dengan Kelompok Karmina yaitu $80 \mathrm{~kg}$, tetapi harga beli lele segar di Kelompok Pamuji per kilogramnya lebih mahal dibandingkan dengan Kelompok Karmina dan Alang-alang yaitu sebesar Rp 18.000, maka biaya yang dikeluarkan untuk bahan baku juga lebih besar. Berbeda dengan Kelompok Alang-alang dan Karmina, harga bahan baku lele segar per kilogramnya lebih murah yaitu sebesar Rp 17.000, sehingga biaya bahan baku yang dikeluarkan lebih sedikit dibandingkan dengan kelompok Pamuji.

Tabel 3. Biaya Variabel Produksi Abon Lele Di Desa Tegalrejo Kecamatan Sawit Kabupaten Boyolali dalam 1 Bulan Produksi

\begin{tabular}{cccc}
\hline Keterangan & \multicolumn{3}{c}{ Biaya Kelompok Usaha (Rp) } \\
& Karmina & Alang-Alang & Pamuji \\
\hline Biaya Bahan Baku & 18.890 .400 & 6.762 .600 & 22.787 .200 \\
Biaya Bahan Bakar & 560.000 & 135.000 & 72000 \\
Biaya Pengemasan & 160.080 & 72000 & 194.880 \\
\hline Biaya Variabel (Variable & $\mathbf{1 9 . 6 1 0 . 4 8 0}$ & $\mathbf{6 . 9 6 9 . 6 0 0}$ & $\mathbf{2 3 . 0 5 4 . 0 8 0}$ \\
Cost) & & &
\end{tabular}

Sumber: Analisis Data Primer, 2018.

Pada rincian biaya bahan bakar yang paling tinggi di Kelompok Karmina karena di Kelompok tersebut menggunakan bahan bakar gas elpiji $12 \mathrm{~kg}$ sedangkan di 2 kelompok lainnya menggunakan bahan bakar gas elpiji $3 \mathrm{~kg}$ sehingga biaya yang dikeluarkan juga lebih sedikit karena perbedaan harga. Gas elpiji 12 harganya adalah Rp 70.000, dan harga gas elpiji $3 \mathrm{~kg}$ harganya adalah Rp 15.000 di Kelompok Alang-alang dan Rp 18.000 di Kelompok Pamuji. Pada rincian biaya pengemasan yang tertinggi di Kelompok pamuji karena semakin banyak jumlah atau unit abon yang diproduksi maka semakin banyak kemasan yang dibutuhkan dan tentunya menambah cost.

c. Analisis Biaya Total

Tabel 4. Biaya Total Produksi Abon Lele Di Desa Tegalrejo Kecamatan Sawit Kabupaten Boyolali dalam 1 Bulan Produksi

\begin{tabular}{cccc}
\hline \multirow{2}{*}{ Keterangan } & \multicolumn{3}{c}{ Biaya Kelompok Usaha (Rp) } \\
& Karmina & Alang-Alang & Pamuji \\
\hline Biaya Tetap & 4.433 .111 & 1.428 .184 & 3.001 .468 \\
Biaya Variabel & 19.610 .480 & 6.969 .600 & 23.054 .080 \\
\hline Biaya Total & $\mathbf{2 4 . 0 4 3 . 5 9 1}$ & $\mathbf{8 . 3 9 7 . 7 8 4}$ & $\mathbf{2 6 . 0 5 5 . 5 4 8}$ \\
\hline
\end{tabular}

Sumber : Analisis Data Primer, 2018.

Berdasarkan analisis biaya total produksi abon lele, dapat diketahui biaya total yang dikeluarkan tertinggi pada kelompok usaha Pamuji dan yang paling sedikit pada kelompok Alang-alang. Hal yang menyebabkan biaya total di Kelompok Usaha Pamuji tinggi adalah biaya bahan baku lele segar. Kelompok Pamuji membutuhkan biaya bahan baku lele segar lebih banyak karena harga beli lele segar yang lebih mahal yaitu Rp 18.000 per kilogram, sedangkan di kelompok Karmina dan Alang-alang harga beli lele lebih murah yaitu sebesar Rp 17.000 per 
kilogram, sehingga biaya bahan baku lele segarnya lebih sedikit dari Kelompok Pamuji.

d. Analisis Penerimaan

Tabel 5. Produksi dan Penerimaan Abon Lele di Desa Tegalrejo Kecamatan Sawit Kabupaten Boyolali dalam 1 bulan

\begin{tabular}{lccc}
\hline \multicolumn{1}{c}{ Keterangan } & \multicolumn{3}{c}{ Penerimaan Kelompok Usaha (Rp) } \\
& Karmina & Alang-Alang & Pamuji \\
\hline Produksi Abon $(\mathrm{kg})$ & 276 & 120 & 336 \\
Harga Abon Per kg $(\mathrm{Rp})$ & 120.000 & 110.000 & 110.000 \\
\hline Total Penerimaan & $\mathbf{3 3 . 1 2 0 . 0 0 0}$ & $\mathbf{1 3 . 2 0 0 . 0 0 0}$ & $\mathbf{3 6 . 9 6 0 . 0 0 0}$ \\
\hline
\end{tabular}

Sumber : Analisis Data Primer, 2018

Berdasarkan Tabel 5 bahwa penerimaan yang diterima dari produksi abon lele selama 1 bulan produksi di Kelompok Usaha Karmina sebesar Rp 33.120.000. Penerimaan diperoleh dari jumlah produksi abon lele dikalikan dengan harga per kg. Produksi abon lele selama 1 bulan di Kelompok Usaha Karmina sebesar 276 $\mathrm{kg}$ dan harga per $\mathrm{kg}$ abon adalah $\mathrm{Rp}$ 120.000. Penerimaan yang diterima dari produksi abon lele selama 1 bulan produksi di Kelompok Usaha Pamuji sebesar Rp 36.690.000. Penerimaan diperoleh dari jumlah produksi abon lele dikalikan dengan harga per kg. Produksi abon lele selama 1 bulan di Kelompok Usaha Pamuji sebesar $336 \mathrm{~kg}$ dan harga per $\mathrm{kg}$ abon adalah Rp 110.000. Penerimaan yang diterima dari produksi abon lele selama 1 bulan produksi di Kelompok Usaha Alang-alang sebesar Rp 13.200.000. Penerimaan diperoleh dari jumlah produksi abon lele dikalikan dengan harga per kg. Produksi abon lele selama 1 bulan di Kelompok Usaha Alang-alang sebesar $120 \mathrm{~kg}$ dan harga per $\mathrm{kg}$ abon adalah Rp 110.000. Hasil penerimaan menunjukkan bahwa Kelompok Usaha Pamuji memperoleh penerimaan yang lebih tinggi karena produksi abon mencapai $336 \mathrm{~kg}$ dengan produksi sebanyak 16 kali dalam 1 bulan dibandingkan di Kelompok Karmina yang hanya memproduksi sebanyak 12 kali dengan jumlah produksi sebanyak $276 \mathrm{~kg}$. Penerimaan terendah diperoleh Kelompok Alang-alang karena produksi dalam 1 bulan hanya 3 kali dan jumlah produksi $120 \mathrm{~kg}$. Harga abon lele di Kelompok Karmina lebih tinggi dibandingkan dengan Kelompok Pamuji dan Alang-alang karena plastik kemasannya lebih baik dengan merk sablon melekat di plastik kemasannya.

e. Analisis Pendapatan

Tabel 6. Pendapatan Produksi Abon Lele di Desa Tegalrejo Kecamatan Sawit Kabupaten Boyolali dalam 1 Bulan

\begin{tabular}{cccc}
\hline Keterangan & \multicolumn{3}{c}{ Pendapatan Kelompok Usaha (Rp) } \\
& Karmina & Alang-Alang & Pamuji \\
\hline Penerimaan & 33.120 .000 & 13.200 .000 & 36.960 .000 \\
Total Biaya & 24.043 .591 & 8.397 .784 & 26.055 .548 \\
\hline Pendapatan & $\mathbf{9 . 0 7 6 . 4 0 8}$ & $\mathbf{4 . 8 0 2 . 2 1 5}$ & $\mathbf{1 0 . 9 0 4 . 4 5 1}$ \\
\hline
\end{tabular}

Sumber : Analisis Data Primer, 2018.

Berdasarkan Tabel 6 bahwa pendapatan yang diperoleh dari produksi abon lele selama 1 bulan di Kelompok Usaha karmina sebesar Rp 9.076.408. Pendapatan diperoleh dari total penerimaan sebesar Rp 33.120.000 dikurangi dengan total biaya produksi abon sebesar Rp 24.043.591. Pendapatan yang 
diperoleh dari produksi abon lele selama 1 bulan di Kelompok Usaha Pamuji sebesar Rp 10.904.451. Pendapatan diperoleh dari total penerimaan sebesar Rp 36.960.000 dikurangi dengan total biaya produksi abon sebesar Rp 26.055.548. Pendapatan yang diperoleh dari produksi abon lele selama 1 bulan di Kelompok Usaha Alang-alang sebesar $\mathrm{Rp}$ 4.802.215. Pendapatan diperoleh dari total penerimaan sebesar Rp 13.200.000 dikurangi dengan total biaya produksi abon sebesar Rp 8.397.784. Berdasarkan analisis pendapatan dapat diketahui bahwa pendapatan tertinggi diperoleh Kelompok Pamuji dan pendapatan terendah diperoleh Kelompok Alang-alang. Kelompok Pamuji memperoleh pendapatan tertinggi karena tingkat produksi abon lele dalam 1 bulan mencapai $336 \mathrm{~kg}$ sehingga revenue yang diterima juga tinggi sedangkan di Kelompok Alang-alang tingkat produksinya lebih rendah yaitu hanya $120 \mathrm{~kg}$ sehingga revenue yang diterima lebih rendah dari Kelompok Pamuji.

Secara umum, berdasarkan analisis pendapatan usaha pengolahan abon lele di Kelompok Karmina, Kelompok Pamuji, dan Kelompok Alang-alang memperoleh pendapatan yang positif sehingga sesuai dengan hipotesis..

f. Analisis R/C

Berdasarkan analisis $\mathrm{R} / \mathrm{C}$ bahwa besarnya nilai $\mathrm{R} / \mathrm{C}$ dari usaha pengolahan abon lele di Kelompok Usaha Karmina adalah 1,37. Nilai tersebut diperoleh dari hasil bagi antara total penerimaan dengan total biaya. Adapun analisisnya sebagai berikut :

$$
\begin{aligned}
& \mathrm{R} / \mathrm{C}=\mathrm{TR} / \mathrm{TC} \\
& \mathrm{R} / \mathrm{C}=33.120 .000 / 24.043 .591 \\
& \mathrm{R} / \mathrm{C}=1,37
\end{aligned}
$$

Nilai R/C di Kelompok Usaha Karmina yaitu 1,37 yang berarti bahwa setiap pengeluaran $\mathrm{Rp} 100$ maka akan mendapatkan penerimaan sebesar $\mathrm{Rp} 137$. Analisis ini juga menunjukkan bahwa nilai R/C $>1$ sehingga usaha pengolahan abon lele di Kelompok Usaha Karmina layak diusahakan.

Besarnya nilai R/C dari usaha pengolahan abon lele di Kelompok Usaha Pamuji adalah 1,41. Nilai tersebut diperoleh dari hasil bagi antara total penerimaan dengan total biaya. Adapun analisisnya sebagai berikut :

$$
\begin{aligned}
& \mathrm{R} / \mathrm{C}=\mathrm{TR} / \mathrm{TC} \\
& \mathrm{R} / \mathrm{C}=36.960 .000 / 26.055 .548 \\
& \mathrm{R} / \mathrm{C}=1,41
\end{aligned}
$$

Nilai R/C di Kelompok Usaha Pamuji adalah 1,41 yang berarti bahwa setiap pengeluaran Rp 100 maka akan memperoleh penerimaan sebesar Rp 141. Nilai $\mathrm{R} / \mathrm{C}$ di Kelompok Usaha Pamuji $>1$ sehingga usaha pengolahan abon lele di Kelompok Pamuji layak diusahakan.

Besarnya nilai R/C dari usaha pengolahan abon lele di Kelompok Usaha Alang-alang adalah 1,57. Nilai tersebut diperoleh dari hasil bagi antara total penerimaan dengan total biaya. Adapun analisisnya sebagai berikut :

$$
\begin{aligned}
& \mathrm{R} / \mathrm{C}=\mathrm{TR} / \mathrm{TC} \\
& \mathrm{R} / \mathrm{C}=13.200 .000 / 8.397 .784 \\
& \mathrm{R} / \mathrm{C}=1,57
\end{aligned}
$$

Nilai R/C di Kelompok Usaha Alang-alang adalah 1,57 yang berarti bahwa setiap pengeluaran Rp 100 maka akan memperoleh penerimaan sebesar Rp 
157. Nilai R/C di Kelompok Usaha Alang-alang $>1$ sehingga usaha pengolahan abon lele di Kelompok Alang-alang layak diusahakan. Berdasarkan analisis R/C di Kelompok Usaha Karmina, Pamuji, dan Alang-alang hasilnya memiliki nilai $\mathrm{R} / \mathrm{C}$ lebih dari 1 sehingga layak diusahakan. Hal ini sesuai dengan hipotesis kedua.

\section{g. Analisis BEP}

BEP (Break Even Point) usaha pengolahan abon lele di Desa Tegalrejo Kecamatan Sawit Kabupaten Boyolali terbagi atas 2 analisis, yaitu berdasarkan unit dan rupiah. Nilai BEP unit di Kelompok Usaha Karmina adalah 200,36 kg dan nilai BEP atas dasar rupiah adalah $\mathrm{Rp}$ 87.114. Nilai tersebut diperoleh dari analisis sebagai berikut :

1. BEP atas dasar unit

$$
\begin{aligned}
\operatorname{BEP}(Q) & =\frac{\text { Total biaya }}{\text { Harga }} \\
& =\frac{24.043 .591,88}{120.000} \\
& =200,36 \mathrm{~kg}
\end{aligned}
$$

2. BEP atas dasar penjualan dalam rupiah

$$
\begin{aligned}
\operatorname{BEP}(\text { rupiah }) & =\frac{\text { Total biaya }}{\text { Jumlah produksi }} \\
& =\frac{24.043 .591,88}{276} \\
& =87.114 / \mathrm{kg}
\end{aligned}
$$

Hasil perhitungan BEP atas dasar unit menunjukkan nilai BEP adalah 200,36 kg yang berarti produksi abon lele di Kelompok Usaha Karmina mencapai titik impas pada saat produksi mencapai $200,36 \mathrm{~kg}$. Hasil perhitungan dari BEP atas dasar penjualan dalam rupiah menunjukkan nilai sebesar Rp 87.114 yang berarti bahwa usaha pengolahan abon lele di Kelompok Usaha Karmina mencapai titik impas bila abon lele dijual dengan harga RP 87.114 per kilogram. Hal ini berarti bahwa industri pengolahan abon lele di Karmina dilihat dari BEP unit sudah mencapai laba karena melebihi batas minimal produksi untuk mencapai titik impas yaitu sebanyak 200,36 kg, padahal produksi di Kelompok Karmina adalah $276 \mathrm{~kg}$ selama 1 bulan, dan dilihat dari analisis BEP rupiah Kelompok Karmina mampu menjual dengan harga Rp 120.000, artinya Kelompok Karmina menetapkan harga yang tinggi dari harga minimalnya yang sebesar Rp 87.114.

Nilai BEP unit di Kelompok Usaha Pamuji adalah 236,86 kg dan nilai BEP atas dasar rupiah adalah Rp 77.546. Nilai tersebut diperoleh dari analisis sebagai berikut :

1. BEP atas dasar unit

$$
\begin{aligned}
\operatorname{BEP}(Q) & =\frac{\text { Total biaya }}{\text { Harga }} \\
& =26.055 .548,5 / 110.000
\end{aligned}
$$




$$
=236,86 \mathrm{~kg}
$$

2. BEP atas dasar penjualan dalam rupiah

$$
\begin{aligned}
\text { BEP (rupiah) } & =\frac{\text { Total biaya }}{\text { Jumlah produksi }} \\
& =25.735 .548 / 336 \\
& =77.546 / \mathrm{kg}
\end{aligned}
$$

Hasil perhitungan BEP atas dasar unit menunjukkan nilai BEP adalah 236,86 $\mathrm{kg}$ yang berarti produksi abon lele di Kelompok Usaha Pamuji mencapai titik impas pada saat produksi mencapai $236,86 \mathrm{~kg}$. Hasil perhitungan dari BEP atas dasar penjualan dalam rupiah menunjukkan nilai sebesar Rp 77.546 yang berarti bahwa usaha pengolahan abon lele di Kelompok Usaha Pamuji mencapai titik impas bila abon lele dijual dengan harga Rp 77.546 per kilogram. Hal ini berarti bahwa industri pengolahan abon lele di Pamuji dilihat dari BEP unit sudah mencapai laba karena melebihi batas minimal produksi untuk mencapai titik impas yaitu sebanyak $236,86 \mathrm{~kg}$, padahal produksi di Kelompok Pamuji adalah $336 \mathrm{~kg}$ selama 1 bulan, dan dilihat dari analisis BEP rupiah Kelompok Pamuji mampu menjual dengan harga Rp 110.000, artinya Kelompok Pamuji menetapkan harga yang tinggi dari harga minimalnya yang sebesar Rp 77.546

Nilai BEP unit di Kelompok Usaha Alang-alang adalah 76,34 kg dan nilai BEP atas dasar rupiah adalah $\mathrm{Rp}$ 69.981. Nilai tersebut diperoleh dari analisis sebagai berikut :

1. BEP atas dasar unit

$$
\begin{aligned}
\operatorname{BEP}(\mathrm{Q}) & =\frac{\text { Total biaya }}{\text { Harga }} \\
& =8.397 .784 / 110.000 \\
& =76,34 \mathrm{~kg}
\end{aligned}
$$

2. BEP atas dasar penjualan dalam rupiah

$$
\begin{aligned}
\text { BEP (rupiah) }=\frac{\text { Total biaya }}{\text { Jumlah produksi }} \\
=8.397 .784 / 120 \\
=69.981 / \mathrm{kg}
\end{aligned}
$$

Hasil perhitungan BEP atas dasar unit menunjukkan nilai BEP adalah $76,34 \mathrm{~kg}$ yang berarti produksi abon lele di Kelompok Usaha Alang-alang mencapai titik impas pada saat produksi mencapai $76,34 \mathrm{~kg}$. Hasil perhitungan dari BEP atas dasar penjualan dalam rupiah menunjukkan nilai sebesar Rp 69.981 yang berarti bahwa usaha pengolahan abon lele di Kelompok Usaha Alang-alang mencapai titik impas bila abon lele dijual dengan harga Rp 69.981 per kilogram. Hal ini berarti bahwa industri pengolahan abon lele di Alang-alang dilihat dari BEP unit sudah mencapai laba karena melebihi batas minimal produksi untuk mencapai titik impas yaitu sebanyak 76,34 kg, padahal produksi di Kelompok Alang-alang adalah $120 \mathrm{~kg}$ selama 1 bulan, dan dilihat dari analisis BEP rupiah Kelompok Alang-alang mampu menjual dengan harga Rp 110.000, artinya Kelompok Alangalang menetapkan harga yang tinggi dari harga minimal. 


\section{KESIMPULAN}

1. Biaya total yang dikeluarkan kelompok usaha abon lele dari masing-masing kelompok usaha Karmina, Pamuji, dan Alang-alang berturut-turut adalah Rp 24.043.591, Rp 26.055.548, dan $\mathrm{Rp}$ 8.397.784 dalam satu bulan produksi. Penerimaan produksi total abon lele di Kelompok Usaha Karmina, Pamuji, dan Alang-alang berturut-turut adalah Rp 33.120.000, Rp 36.960.000, dan Rp 13.200.000 dalam satu bulan produksi. Pendapatan yang diterima dari produksi abon lele di Kelompok Karmina, Pamuji, dan Alang-alang berturutturut adalah $\mathrm{Rp}$ 9.076.408, Rp 10.904.451, dan Rp 4.802.215 dalam satu bulan produksi.

2. Nilai R/C usaha pengolahan abon lele dari masing-masing kelompok usaha Karmina, Pamuji, dan Alang-alang berturut-turut adalah 1,37; 1,41; dan 1,57. Secara umum usaha pengolahan abon lele di Desa Tegalrejo Kecamatan Sawit Kabupaten Boyolali layak diusahakan. BEP unit yang diperoleh dari Kelompok karmina adalah 200,36 kg dengan harga jual Rp 120.000 kelompok tersebut mengeluarkan biaya total sebesar Rp 24.043.591 untuk mencapai titik impas sedangkan BEP unit yang diperoleh dari Kelompok Pamuji adalah 236,86 kg dengan harga Rp 110.000 kelompok tersebut mengeluarkan biaya sebesar Rp 26.055.548 untuk mencapai titik impas. BEP unit yang diperoleh dari Kelompok Alang-alang adalah 76,34 dengan harga jual $\mathrm{Rp} 110.000$ kelompok tersebut mengeluarkan biaya total sebesar $\mathrm{Rp}$ 8.397.784 untuk mencapai titik impas. BEP berdasarkan penjualan atas dasar rupiah dari kelompok Karmina adalah Rp 87.114/kg untuk mencapai titik impas, kelompok Pamuji Rp 77.546 untuk mencapai titik impas, dan dari kelompok Alang-alang Rp 69.981/kg untuk mencapai titik impas.

\section{DAFTAR PUSTAKA}

BPS. (2016). Kabupaten Boyolali Dalam Angka 2016. Badan Pusat Statistik. Boyolali.

DJPB. (2011). Statistik Produksi Perikanan Budidaya Indonesia. www.djpb.kkp.go.id, diakses tanggal 2 Maret 2018.

Mesra .(2012). Penerapan Ilmu Matematika Dalam Ekonomi dan Bisnis. Yogyakarta : CV.Budi Utama.

Nazir, M. (2005). Metode Penelitian Sosial. Jakarta: Erlangga.

Soekartawi. (2002). Analisis Usaha Tani. Jakarta: UI Press.

Supardi. (2000). Teori Biaya. Yogyakarta: Kanisius.

Supardi. (2005). Metode Penelitian. Jakarta: Erlangga.

Supranto. (2000). Statistik Teori dan Aplikasi. Jakarta. Erlangga. 